\title{
Valorização da enfermagem brasileira: analisando aspectos históricos e de gênero
}

RESUMO | Objetivo: Contribuir para a compreensão e reflexão sobre a valorização da enfermagem, perpassando por aspectos históricos e de gênero. Método: Revisão Integrativa. Buscas 2013 - 2018, idiomas português, espanhol e inglês. Após seleção refinada 13 artigos foram utilizados na discussão. Resultados: Por ser predominantemente feminina a opressão social tem força esmagadora na concepção de enfermagem. Entender os aspectos aos quais a enfermagem está sujeita, influencia a força da enfermeira para decidir e construir seu futuro profissional e lutar por modificações e valorização. Conclusão: O estudo da história e da influência dos papéis de gênero relacionam-se à opressão social da enfermeira e são imprescindíveis para a formação crítica. Palavras-chaves: Enfermagem; Identidade de Gênero; Feminismo; Sexismo; Prática Profissional.

ABSTRACT | Objective: To contribute to the understanding and reflection on the valorization of nursing, going through historical and gender aspects. Method: Integrative Review. Searches 2013 - 2018, Portuguese, Spanish and English languages. After refined selection, 13 articles were used in the discussion. Results: Because social oppression is predominantly female, it has an overwhelming force in the concept of nursing. Understanding the aspects that nursing is subject to, influences the strength of the nurse to decide and build her professional future and fight for changes and valorization. Conclusion: The study of history and the influence of gender roles are related to the social oppression of nurses and are essential for critical training.

Keywords: Nursing; Gender Identity; Feminism; Sexism; Professional Practice.

RESUMEN | Objetivo: Contribuir a la comprensión y reflexión sobre la valorización de la enfermería, pasando por aspectos históricos y de género. Método: revisión integradora. Búsquedas 2013-2018, portugués, español e inglés. Después de una selección refinada, se utilizaron 13 artículos en la discusión. Resultados: Debido a que la opresión social es predominantemente femenina, tiene una fuerza abrumadora en el concepto de enfermería. Comprender los aspectos a los que está sujeta la enfermería influye en la fortaleza de la enfermera para decidir y construir su futuro profesional y luchar por los cambios y la valorización. Conclusión: El estudio de la historia y la influencia de los roles de género están relacionados con la opresión social de las enfermeras y son esenciales para la capacitación crítica.

Descriptores: Enfermería; Identidad de género; Feminismo; Sexismo; Práctica profesional

\section{Sara Caroline Ribeiro Gugel}

Graduação em Enfermagem - Universidade Federal de Goiás.

\section{Celia Scapin Duarte}

Enfermeira, PhD Doutora - Universidade Federal de Goiás, docente da Universidade Federal de Pelotas.

\section{Ana Paula Lopes Lima}

Enfermeira, Mestra - Universidade Federal de Goiás, Docente do Centro Universitário de Goiatuba Unicerrado.

Recebido em: 19/03/2020

Aprovado em: 23/03/2020

\section{INTRODUÇÃO}

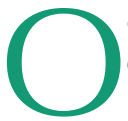
contexto do exercício da enfermagem está diretamente ligado às qualidades femininas determinadas por papéis de gênero associados ao modelo de enfermagem pré-moderna e pré-capitalista ${ }^{(1)}$. O trabalho da enfermagem era vinculado ao trabalho da mulher, tendo como resultado a desvalorização e invisibilidade ${ }^{(2,3)}$.

A enfermagem moderna instituída por Florence Nightingale determinava que a enfermeira deveria cumprir com rigor as determinações médicas ${ }^{(4)}$ e em sua origem, a enfermagem brasileira reproduziu estes conceitos com caráter dogmático religioso. A formação das enfermeiras brasileiras, foi embasada em atividades de repetições práticas e desassociadas a teoria, reduzindo a possibilidade de desenvolvimento da criatividade e saber cientifico próprio reforçando as diferenças entre enfermeiras e médicos, agravando a subalternização baseada no gênero ${ }^{(5)}$. Entendemos gênero em dois níveis: o primeiro como elemento constitutivo das relações sociais, baseado nos diferentes papéis exercidos pelos sexos masculino e feminino, e o segundo como representante das relações de poder em que forças dominantes são tidas como naturais e indubitáveis que atribui significado as relações de poder ${ }^{(6,7)}$.

A relevância da atuação da enfermagem por vezes não é considerada, é preciso compreender e destacar a identidade da mesma, favorecendo sua afirmação, estimulando que a sociedade e os profissionais de enfermagem tenham consciência da grandeza de sua história, conquistas, lutas, de seu saber e de seu objeto de trabalho, o cuidar. Neste sentido, o objetivo deste estudo é contribuir para a compreensão e reflexão sobre a valorização da enfermagem, perpassando por aspectos históricos e de gênero, afim de contribuir para o avanço na valorização, respeito e reconhecimento da profissão. 
MÉTODO

Trata-se de uma revisão integrativa, cujo método é composto por dados secundários, baseado em estudos primários, seguiu-se etapas pré-determinadas como elaboração da questão de pesquisa; amostragem e estabelecimentos dos critérios de inclusão e exclusão; categorização dos estudos, análise ${ }^{(8)}$. Definiu-se como a pergunta do estudo: Quais são os fatores que interferem na valorização da enfermagem brasileira? As buscas foram realizadas nos meses de junho a novembro de 2018, nas bases de dados da Biblioteca Virtual em Saúde (BVS), Literatura Latino-Americana do Caribe em Ciências da Saúde (LILACS), Index Medicus Eletrônico da National Library of Medicine (MEDLINE) e Scientific Electronic Library Online (SciELO) utilizando os seguintes descritores: Enfermagem; História da Enfermagem; Identidade de Gênero; Feminismo; Sexismo; Prática Profissional. Critérios de inclusão: publicações entre 2013 e 2018, nos idiomas português, espanhol e inglês, presença de algum dos descritores no título, metodologia e discussão coesas com a questão norteadora. Critérios de exclusão: artigos que não contemplaram a questão norteadora, historiografia de personalidades especificas e não abordassem a história da enfermagem como profissão.

\section{RESULTADOS}

Diante da combinação dos descritores através do operador booleano "AND" foram encontradas 55 pesquisas, publicações duplicadas foram eliminadas, sendo consideradas as que estavam disponíveis em texto completo. Foi realizada leitura prévia e seleção restando 32 estudos. Em leitura minuciosa das publicações e aplicação dos critérios de inclusão e exclusão restaram 13 estudos. Em seguida, procedeu-se a extração das evidências relativas aos aspectos históricos e de gênero contidos nos artigos selecionados, por meio da leitura de cada artigo realizada por pares, foram separadas e transcritas, frases, palavras e conceitos que correspondiam a elementos de interesse e realizada a comparação entre os mesmos.

\section{DISCUSSÃO}

Enfermagem Pré-moderna e Enfermagem Moderna

A história da enfermagem no período pré-capitalista e pré-profissional estava ligada às atividades domésticas, à mer $\neg$ cê do empirismo, em alguns momentos associada a pessoas de baixo valor e estima social, como prostitutas e bêbados. Diferente da prática médica que se caracterizou pela teorização e preparo para o exercício(4).

Florence Nightingale apresenta que o estabelecimento do saber em enfermagem não modificaria o papel esperado pelas enfermeiras ou pelas mulheres na sociedade em que se encontrava ${ }^{(4,9)}$ :

[..] ninguém pense, entretanto, que a obediência ao médico não é abso-lutamente necessária. Apenas nem o médico nem a enfermeira enfatizam suficientemente a obediência inteligente e de a mera obediência ser mui-to pouco [...] ${ }^{(9)}$.

A enfermagem moderna nestes parâmetros está cheia de estereótipos de gênero, a mulher era tida como sombra discreta e subordinada no espaço hospitalar. A afirmação destas características da enfermeira semelhante a Maria, mãe virgem, pura e assexuada, tinha como intuito "limpar" o momento da história em que a profissão foi exercida por pessoas menos favorecidas e que buscavam a redenção cuidando dos doentes ${ }^{(4,10)}$.

\section{Enfermagem no Brasil}

No Brasil a enfermagem era empírica e informal, fato que começou a ser mudado com a saída das irmãs de caridade do Hospício Nacional de Alienados (HNA) e a contratação de enfermeiras francesas da Escola de Salpêtrière e a criação da Escola Profissional de Enfermeiros e En- fermeiras (EPEE) influenciada pelo padrão de enfermagem do Dr Bourneville, cujo modelo visava formar "religiosas sem hábito", cuidadoras devotadas e cumpridoras das prescrições médicas ${ }^{(11,12)}$. A Fundação Rockefeller e o modelo norte americano também exerceram influência na enfermagem brasileira ${ }^{(1)}$. Em 1920, 13 enfermeiras foram responsáveis pela criação da Escola de Enfermeiras do Departamento Nacional de Saúde Pública, mais tarde Escola Anna Nery ${ }^{(1,4)}$, destinada às mulheres da alta sociedade, era necessária estabilidade emocional, distinção moral e apresentação respeitosa ${ }^{(11)}$. As egressas do curso de enfermagem obtinham diploma de nível médio e a escola foi incorporada à Universidade do Brasil em 1946 e em 1962 se estabeleceu como sendo de ensino superior ${ }^{(4)}$. $O$ fato de permanecer como curso de nível médio associa-se com a educação feminina restrita na época e ao fato de não haver estímulos ao aprimoramento educacional, seria mais adequado que elas ocupassem um lugar em uma escola de enfermagem do que atingissem o segundo grau e pudessem alcançar qualquer outro curso superior, induzindo as escolhas profissionais das mulheres.

Após a formatura da primeira turma da Escola Anna Nery foi fundada a Associação Brasileira de Enfermeiras Diplomadas (ABED) em 1926, em 1952 tornou-se órgão de utilidade pública e em 1954 mudou seu nome para Associação Brasileira de Enfermagem (ABEn) ${ }^{(4)}$. Em 1938, Getúlio Vargas criou o Dia do Enfermeiro afirmando que deveriam ser prestadas homenagens a enfermeira brasileira Anna Nery em todos os locais onde a enfermagem fosse exercida, aplicando a indução de ideais religiosos e patrióticos como essência da enfermagem(1) e os ritos institucionais estabelecidos a partir dali tiveram a função de manipular e construir um ideário de poder, associando determinadas imagens ${ }^{(13)}$. A demora da organização do caráter científico comprometeu a valorização da profissão, a enfermagem ainda era vista como um saber comple- 
mentar, ocupando um lugar que qualquer pessoa leiga poderia preencher.

Na Segunda Guerra Mundial foi criado o primeiro grupo feminino de enfermagem militar brasileira em $1942^{(14)}$ cujo a presença nas guerras expõe a contradição da ditadura em relação ao papel social das mulheres, sua permanência ali se "justifica" reafirmando os papéis sociais, com homens no front da batalha e mulheres na retaguarda ${ }^{(1)}$.

\section{Gênero e enfermagem}

Goodman $^{(10)}$ argumenta que o contexto social, econômico e fisiológico deve ser levado em consideração ao analisar os papéis distintos de gênero estabelecidos e Saffioti ${ }^{(15)}$ refere que os papéis de gênero devem ser cumpridos, existindo uma delimitação exata em relação aos campos em que podem atuar. No entanto uma enfermeira enclausurada nos estereótipos de gênero e com estímulo a sua consciência crítica restrito por vezes é incapaz de ver determinadas situações que a cercam. Quando gênero é considerado uma construção sociológica, política e cultural, o sexo não poderia ser pensado como uma variável demográfica, biológica ou natural, mas sim como uma junção de fatores culturais e ideológicos formados em cada período histórico de maneiras diferentes(7). A determinação de como os símbolos do gênero influenciaram a construção social da imagem da enfermagem deve ser entendida para que possamos atuar nestes fatores diretamente, e mudar destinos que são apresentados, falaciosamente, como única perspectiva possível.

Influência da Igreja Católica no exercício da enfermagem

O poder da igreja no Brasil pode ser percebido com o Decreto 22.257 de 26 de dezembro, 1932 que autorizava as Irmãs de Caridade a exercerem atividades de enfermagem caso tivessem no mínimo seis anos de prática(1). Com relação à formação acadêmica, Almeida et al (5) coletou depoimentos de enfermeiras militantes reconhecidas, muitas delas ex-presidentes da ABEN:
[...] ética na Escola de Enfermagem era preceito da religião. [...], mas era sobre a vida de santo, eram coisas ligadas à religião católica. Levava padre para fazer conferências nas aulas de ética. [...]

[...] a influência da igreja católica, onde a cobrança do trabalho das freiras se dava indiretamente, e o valor econômico do trabalho da Enfermagem não era colocado, gerou uma categoria bastante submissa, acomodada, com momentos de militância esporádica. [...] a questão religiosa [...] trouxe vários problemas e citaria apenas dois: a submissão e a subalternidade, pois grande parte delas trabalhava por troca de residência e fazer o bem, não é por acaso que hoje tem os símbolos de anjos. [... ${ }^{(5)}$.

Em 1958 no primeiro Código de Ética da Enfermagem, caracterizava a enfermagem como missão, ao invés de profissão a ser exercida com cientificidade. Substitui a particularidade caritativa, pela vocação que mantém a enfermagem submissa a outras categorias profissionais ${ }^{(4)}$. Em 1975 o Código de Infrações e Penalidade não autorizava que enfermeiras participassem de propagandas, que recebessem gratificações pelo seu trabalho, que criticassem uma colega ou a instituição onde exerciam seu trabalho, que participassem ou promovessem abortos entre outras restrições ${ }^{(4)}$.

Visibilidade e valorização profissional Fowler ${ }^{(16)}$ relata que a enfermagem tem seu progresso associado ao das mulheres, precisou de muita luta para que a profissão evoluísse ao patamar em que se encontra. Ser enfermeira, mesmo que não seja compreensível para muitas, é carregar marcas do feminismo em si. Aos poucos o senso coletivo e o fortalecimento mútuo entre enfermeiras são formados ${ }^{(16)}$. O não reconhecimento da relevância do trabalho da enfermagem pela sociedade e demais profissionais de saúde tem ligação com os aspectos históricos negligenciados, inclusive na gradua- ção, e com o fato de o cuidar científico ter se estabelecido tardiamente ${ }^{(17)}$. Lombardi e Campos $^{(12)}$ apresentam uma descrição do porquê a enfermagem seria uma profissão com problemas para ser valorizada:

[...] A enfermagem é trabalho de mulheres, lida com o cuidado do outro, é um trabalho subordinado à autoridade médica, foi por longo tempo identificado com as atividades domésticas $[\ldots]^{(12)}$.

Em sua conclusão, escrita em 2018 apresenta "[...] outro fator que joga na desvalorização da área da enfermagem reside na sua relação historicamente assimétrica com a medicina, à qual está subordinada e, portanto, a cuja autoridade deve se submeter. [...]" ${ }^{\prime 12)}$. É necessário entender a contribuição do estudo da história da enfermagem na valorização da profissão. Marinelli et al ${ }^{(17)}$ fomenta em sua conclusão:

[...] Ainda são escassas as pesquisas que envolvem a temática História da Enfermagem e sua relevância para a consolidação da profissão, sendo necessário que mais trabalhos sejam feitos afim de que se divulguem as informações e se ampliem o conhecimento na área. [...] ${ }^{(17)}$

O desconhecimento do que é a enfermagem e sua atuação, reduz a visibilidade da mesma, interferindo na autonomia e isso se relaciona a sua história, falta de reconhecimento do embasamento cientifico, divulgação de uma imagem pela mídia que não condiz com o real, e a não realização de marketing pessoal pelo profissional de enfermagem, postura equivocada perante a equipe de saúde e a sobrecarga de trabalho ${ }^{(18)}$.

\section{Atuação política da enfermagem}

No Brasil, ao longo das décadas de 1940 e 1960 houve a hierarquização da profissão e a luta entre os níveis diferentes de formação enfraqueceu politicamente a profissão. Somente na década de 1980 o 
caráter conservador começou a deixar as instituições associativas ${ }^{(4)}$. Quando ocorreu esta mudança de panorama as enfermeiras e estudantes que atuavam politicamente passaram a ser hostilmente tratadas ${ }^{(5)}$ :

“Então, também fui chamada várias vezes, pela coordenadora do curso, [...] sempre me hostilizando como uma pessoa que militava na $A B E n$ como se fosse um crime. [...]" (5).

Ainda existem lutas em aberto e pautas a serem discutidas, como a definição nacional da carga horária de trabalho e piso salarial. O que foi exposto até o momento conflui para o fato de as conquistas da enfermagem historicamente passarem por sobrecarga de trabalho, resultando em uma profissão desmobilizada politicamente. Se faz necessária a produção e busca de políticas que estimulem a criticidade das enfermeiras para a conscientização de sua categoria e classe.

\section{Modificações esperadas}

Tudo o que foi discorrido, não somente é uma apresentação de fatos históricos da enfermagem, mas também "um lembrete de quem a enfermagem é" (16) e que toda a sua história é especifica trazendo à tona diversas bandeiras de luta que não podem ser desvinculadas da atuação(16). A definição do que é a enfermagem determina quem vai ser a enfermeira, e o exercício e atuação política da enfermeira definem a enfermagem ${ }^{(5)}$. Entender os aspectos aos quais a enfermagem está sujeita, influencia na força da enfermeira para decidir e construir seu futuro profissional e lutar por modificações sociais e uma enfermagem mais valorizada ${ }^{(5)}$.

\section{CONSIDERAÇÕES FINAIS}

As contribuições acerca da valorização da profissão evidenciam a necessidade de aprofundamento nos estudos da história da enfermagem, a história que precisamos retomar nos cursos de graduação é a que foi brevemente apresentada, que vai além dos fatos considerados relevantes. Enfermeiras sendo capazes de reconhecer os fatores históricos e sociais que condicionam seu comportamento são capazes de romper as amarras e lutar por uma enfermagem valorizada e reconhecida.

\section{Referências}

1. Santos, TCF et al. Rituales patrióticos y religiosos: contribución a la identidad de las enfermeras brasileña y española (1937-1945). Esc. Anna Nery. Mar, 2013;17:104-110. Disponível em: http://www.scielo.br/scielo.php?script=sci_arttext\&pi$\mathrm{d}=\mathrm{S} 1414-81452013000100015 \& \mathrm{lng}=\mathrm{en} \& \mathrm{nrm}=\mathrm{iso}>$. Acesso em 15 Nov. 2018. http://dx.doi.org/10.1590/S1414-81452013000100015.

2. Hagell, E. Nursing knowledge: women's knowledge. A sociological perspective. J. Adv. Nurs. 1989;14:226-233. Disponível em: https:// onlinelibrary.wiley.com/doi/abs/10.1111/j.1365-2648.1989.tb01529.x Acesso em 14 nov. 2018

3. Foucault, M. O Nascimento do Hospital. In Foucault, M. Microfísica do Poder. 3.ed. Rio de Janeiro: Graal, 1982.

4. Passos, E. De anjos a mulheres: ideologias e valores na formação de enfermeiras. 2 ed. Salvador: EDUFBA, 2012, 198p.

5. Almeida, DB, et al. Recursos de disciplinarização na enfermagem: um estudo histórico e foucaultiano. Acta Paulista de Enf. 2017; v 30(6):598-606. Disponível em: http://www.scielo.br/scielo.php?pi$\mathrm{d}=\mathrm{S} 010321002017000600598 \&$ script=sci_abstract\&tIng=pt Acesso em 14 nov. 2018

6. Scott J. Gênero: uma categoria útil de análise histórica. Recife: SOS Corpo; 1995.

7. Egry EY, Fonseca RMG Serpa, Oliveira MAC. Ciência, Saúde Coletiva e Enfermagem: destacando as categorias gênero e geração na episteme da práxis. Rev. bras. enferm. [Internet]. 2013. Disponível em: http://www.scielo.br/scielo.php?script=sci_arttext\&pi$\mathrm{d}=$ S003471672013000700016\&lng=en. http://dx.doi.org/10.1590/ S0034-71672013000700016.

8. Souza Marcela Tavares de, Silva Michelly Dias da, Carvalho Rachel de. Revisão integrativa: o que é e como fazer. Einstein (São Paulo) [Internet]. 2010 Mar [cited 2020 Mar 24] ; 8( 1 ): 102-106. Available from: http://www.scielo.br/scielo.php?script=sci_arttext\&pi$\mathrm{d}=$ S1679-45082010000100102\&lng=en. https://doi.org/10.1590/ s1679-45082010rw1134.

9. Nightingale, Florence. Notas sobre enfermagem. São Paulo: Cortez, 1984.

10. Goodman, B. Simone de Beauvoir: A woman's place in nursing?
Nurse education today. 2015; 35:729-730. Disponivel em: https://www. sciencedirect.com/journal/nurse-education-today/vol/35/issue/6. Acesso em 10 nov. 2018

11. Santo, EB, Oguisso T, Fonseca RMGS. A profissionalização da enfermagem brasileira na mídia escrita no final do século XIX: uma análise de gênero. Revista Latino-Americana de Enfermagem, 2011. Disponível em: http://www.scielo.br/pdf/rlae/v19n5/pt_26.pdf

12. Lombardi, MR., Campos, VP. A enfermagem no Brasil e os contornos de gênero, raça/cor e classe social na formação do campo profissional. Revista da ABET. 2018;17. Disponível em: http://www.periodicos.ufpb. br/index.php/abet/article/view/41162.

13. Kneodler, TS, Paes, GO, Porto, FR., Nassar, PRB e Oliveira, AB. A enfermagem em tempos de guerra: propaganda política e valorização profissional (1942-1945). Revista Brasileira de Enfermagem. 2017;70. Disponível em: http://www.scielo.br/pdf/reben/v70n2/pt_ 0034-7167-reben-70-02-0407.pdf

14. Avila LI, Silveira RS, Lunardi VL, Fernandes GFM, Mancia JR, Silveira JT. Implicações da visibilidade da enfermagem no exercício profissional. Rev Gaúcha Enferm. 2013;34:102-109. Disponível em https://seer. ufrgs.br/RevistaGauchadeEnfermagem/article/view/37874 Acesso em 13 nov. 2018.

15. Saffioti, HIB. A mulher na estrutura social de classes. Quatro Artes, 1968. Disponível em:https://edisciplinas.usp.br/pluginfile.php/3825626/mod_resource/content/1/Saffioti $\% 20$ $\% 281978 \% 29 \% 20$ A_Mulher_na_Soc_Classes.pdf Acesso em 10 nov. 2018.

16. Fowler, MD. 'Unladylike Commotion': Early feminism and nursing's role in gender/trans dialogue. Nursing inquiry. 2017;24:121-179.

17. Marinelli, NP, et al. The meaning of the nursing history for vocational training. Revista de Enfermagem da UFPI. 2017;6:61-64. Disponível em: http://www.ojs.ufpi.br/index.php/reufpi/article/viewFile/5098/pdf Acesso em 10 nov. 2018.

18. Girvin, J, Jackson, D e Hutchinson, M. Contemporary public perceptions of nursing: a systematic review and narrative synthesis of the international research evidence. Journal of nursing management, 2016;24:994-1006. 